\section{Baixa diversidade de zooplâncton na desembocadura de uma represa eutrófica (SP, Brasil): reflexo da poluição?}

\author{
Low diversity of zooplankton in the river mouth of an \\ eutrophic reservoir (SP, Brazil): pollution effects?
}

Rosângela Lopes Zaganini ${ }^{[a]}$, Gilmar Perbiche-Neves ${ }^{[\mathrm{b}]}$, Danilo Augusto de Oliveira Naliato ${ }^{[\mathrm{c}]}$, Edmir Daniel Carvalho ${ }^{[\mathrm{d}]}$

\section{Resumo}

0 Rio Tietê (SP) recebe grande parte dos efluentes orgânicos da região metropolitana de São Paulo sendo que o reservatório de Barra Bonita, a mais de 200 km, retém e recicla grande parte desta carga de poluentes. Este trabalho estudou atributos ecológicos da comunidade de zooplâncton (Rotifera, Cladocera e Copepoda), amostrada no trecho entre a desembocadura do citado rio com o reservatório. Foram realizadas coletas mensais entre abril de 2007/fevereiro de 2008. A hipótese testada foi que a comunidade de zooplâncton suporta o forte impacto da poluição, assemelhando-se quali-quantitativamente com outros compartimentos longitudinais do reservatório (intermediário e lacustre sensu Thornton) e outros reservatórios da bacia do alto Rio Paraná. Em termos hidrológicos, o reservatório apresentou uma variação típica de bacia de acumulação, com ampla variação da cota altimétrica sazonal e maior vazão no período chuvoso, influenciado pelo regime pluviométrico, que indicaram relações de efeito sobre a assembleia zooplanctônica. Foram registradas 24 espécies, entre as quais 12 de Rotifera, 8 de Cladocera e 4 de Copepoda. Dados apresentados indicam que a hipótese formulada deve ser rejeitada, pois as tendências de variação dos atributos ecológicos da comunidade de zooplâncton não foram regulares, com valores de abundância relativamente elevados para um ambiente lótico em determinados períodos e baixa abundância ou ausência de organismos em outros. Pode-se inferir que essa situação pode ser reflexo das cargas poluidoras que induzem a baixa concentração de oxigênio dissolvido $\left(>4 \mathrm{mg} . \mathrm{I}^{-1}\right)$ em certos períodos, sendo a comunidade de zooplâncton bastante afetada.

Palavras-chave: Represa. Plâncton. Lótico. Eutrófico. Efluentes.

\begin{abstract}
The Tietê River (in São Paulo state) receives most of the effluents of the metropolitan region of São Paulo; and the Barra Bonita reservoir, $200 \mathrm{~km}$ distant downstream, receives and recycle most of that pollution load. This work studied the ecological features of the zooplankton (Rotifera, Cladocera and Copepoda) sampled in a point of Tietê River's mouth. Monthly samples were collected, from April, 2001 to February, 2008. The hypothesis currently tested was that the composition and availability of zooplankton were similar to the others reservoir regions (middle and lacustrine sensu Thornton) and to other reservoirs of the Upper Paraná River basin, supporting the idea that these organisms manage to stand the strong pollution. The reservoir shows a typical variation of accumulation, with wide variation of seasonal altimetric grading and large flow in the rainy period, influenced by the rainfall regime, with effects upon zooplankton assemblage. As a whole, 24 species were registered: 12 Rotifera, 8 Cladocera and 4 Copepoda. Data showed that the hypothesis formulated must be rejected, due the variation trends of zooplankton environmental attributes not being regular, with relatively high abundance values for a lotic environment in specific months, and low organism abundance or absence in other months. Those facts can be attributed to pollution effects conducting to low dissolved oxygen concentration (> 4mg.l-1) in some months, which causes the zooplankton community to be very much affected.
\end{abstract}

Keywords: Reservoir. Plankton. Lotic. Eutrophic. Effluents.

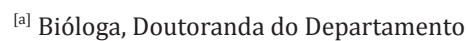
de Ciências Biológicas da Universidade Estadual Paulista Júlio de Mesquita Filho (UNESP), São Paulo, SP - Brasil, e-mail: rozaganini@yahoo.com.br

${ }^{[b]}$ Biólogo, Doutor do Departamento de Zoologia, Instituto de Biociências, Universidade Estadual Paulista Júlio de Mesquita Filho (UNESP), São Paulo, SP Brasil, e-mail: perbiche@ibb.unesp.br ${ }^{[c]}$ Biólogo, Mestre do Departamento de Zoologia, Instituto de Biociências, Universidade Estadual Paulista Júlio de Mesquita Filho (UNESP), São Paulo, SP Brasil, e-mail: naliatobio@yahoo.com.br

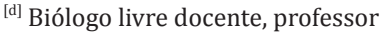
adjunto, Departamento de Morfologia, Instituto de Biociências, Universidade Estadual Paulista Júlio de Mesquita Filho (UNESP), São Paulo, SP - Brasil, e-mail: carvalho@ibb.unesp.br

Recebido: 14/10/2010

Received: 10/14/2010

Aprovado: 27/01/2011

Approved: 01/27/2011 


\section{Introdução}

A construção de reservatórios provoca marcantes modificações nas bacias hidrográficas. No corpo principal de um rio represado pode-se observar a formação de compartimentos longitudinais, transversais e horizontais de grande complexidade espacial e temporal. Alterações na velocidade do fluxo, profundidade, largura, sedimentação de partículas, transparência e penetração de luz e estratificação térmica são exemplos de modificações em relação ao antigo sistema lótico (1). Tais modificações refletem-se na estrutura das comunidades bióticas, inclusive na zooplanctônica (2).

Segundo Thornton (3), normalmente ocorre a formação de três compartimentos ao longo do eixo principal de um reservatório: um lêntico e um intermediário (semilêntico), bastante influenciados pelo represamento do rio, com fluxo reduzido da água, maior tempo de residência, baixa turbidez e geralmente alta abundância e riqueza de organismos planctônicos; e outro ambiente chamado de lótico ou zona de desembocadura, ainda com características de rio, fluxo rápido, baixo tempo de residência da água, alta turbidez e reduzida abundância e riqueza de organismos planctônicos.

No Brasil, existem poucos trabalhos referentes a ecologia do zooplâncton em zonas de desembocadura de represas. Destacam-se alguns realizados em uma grande represa oligo/mesotrófica (Reservatório de Jurumim, Rio Paranapanema-SP), no qual Panarelli (4) enfocou o zooplâncton ao longo de gradiente longitudinal com pontos de amostragem na região de desembocadura; e de Casanova and Henry (5) que estudaram atributos ecológicos de copépodes Cyclopoida e Calanoida no canal do rio e lagoas marginais desse reservatório; Martins and Henry (6) avaliaram a composição do zooplâncton em uma lagoa marginal associada à desembocadura; e DeNadai and Henry (7) as alterações ecológicas na estrutura do zooplâncton após um evento de estiagem aguda nessa bacia hidrográfica.

Em especial, na represa de Barra Bonita (SP), primeiro grande reservatório na cascata de seis no eixo principal do Rio Tietê, diversos estudos contemplaram aspectos limnológicos, tais como: processos de eutrofização (8), bacterioplâncton (9), plâncton (10), entre outros. A represa recebe forte influência do despejo de efluentes principalmente da região metropolitana da grande São Paulo (c.a. 20 milhões de habitantes), situada a aproximadamente $200 \mathrm{~km}$ a sua montante. Nesse trecho, existem algumas pequenas usinas hidrelétricas com baixo tempo de residência. Atualmente, essa represa é caracterizada como eutrófica decorrente da forte pressão antrópica ao longo dos anos que ocasionou profundas alterações nos padrões de biodiversidade (8).

Em relação à comunidade zooplanctônica, há várias pesquisas desenvolvidas. Matsumura-Tundisi and Tundisi (10) encontraram 37 espécies de zooplâncton, porém amostraram apenas a zona semilêntica. A maior parte dos estudos realizados represa não abrangeu a zona lótica propriamente dita, que é representada pelos dois rios tributários principais, o Tietê e o Piracicaba. Esses autores consideram o Rio Tietê um dos mais poluídos do mundo, e a represa (e a barragem) de Barra Bonita favorece o acúmulo dos poluentes graças à diminuição da velocidade da água e sedimentação das partículas, ocorrendo uma melhoria gradativa da qualidade da água ao longo do rio à jusante até a sua foz no Rio Paraná (11).

0 objetivo deste estudo foi caracterizar a composição e abundância da comunidade de zooplâncton, assim como suas relações com variáveis ambientais, no trecho lótico entre a desembocadura do Rio Tietê com a represa de Barra Bonita, e testar a hipótese de que a comunidade de zooplâncton consegue suportar o forte impacto da poluição orgânica, assemelhando-se quali-quantitativamente com os outros compartimentos longitudinais da represa (intermediário e lacustre sensu Thornton) e outras represas da bacia do alto Rio Paraná.

\section{Material e métodos}

\section{Área de estudo e amostragens}

A represa de Barra Bonita (médio Rio Tietê, SP) possui área alagada de $325 \mathrm{~km}^{2}$, profundidade média de 10,2 m e máxima de $25 \mathrm{~m}$ e tempo médio de residência de 100 dias. Para maiores detalhes limnológicos e do zooplâncton nesse reservatório, ver Matsumura-Tundisi and Tundisi $(10,12)$, Tundisi (13), Santos-Wisniewski and Rocha (14) e Tundisi (8).

0 local das amostragens para este estudo (22 $49^{\prime} 22,34^{\prime \prime}$; $\left.48^{\circ} 05^{\prime} 02,84^{\prime \prime} 0\right)$ situa-se no trecho entre a desembocadura o rio com a represa, distante cerca de $60 \mathrm{~km}$ à montante de sua barragem, junto ao município de Anhembi (SP). No local, a profundidade média foi de $4,5 \mathrm{~m}$ e a largura média do canal do rio/ represa foi de $90 \mathrm{~m}$, destacando-se a predominância de condições lóticas. Nesse trecho, ainda existem diversas lagoas adjacentes à montante e à jusante do 
local de coleta. As amostras de zooplâncton foram obtidas mensalmente, entre abr. 2007/fev. 2008. A coleta de zooplâncton foi realizada por meio de arrastos verticais desde o fundo até a superfície, utilizando-se uma rede de plâncton cônica de $50 \mu \mathrm{m}$ de abertura de malha, visando a amostrar toda a coluna de água. Em média foram filtrados 200 litros de água, sendo o material filtrado acondicionado em frascos plásticos devidamente identificados e fixado com formol $4 \%$.

Em cada coleta, algumas variáveis físico-químicas (temperatura, $\mathrm{pH}$, condutividade elétrica, turbidez, oxigênio dissolvido e potencial de óxido redução) e transparência da água foram mensuradas, respectivamente, com o uso de sonda multiparâmetros Horiba U22 e do disco de Secchi (transparência em metros). Também foram obtidas amostras de água (1 litro) para determinação do teor de clorofila-a em laboratório (15). Ainda, outros dados ambientais e hidrológicos como precipitação pluviométrica, cota altimétrica e vazão defluente relativos ao período de estudo, foram cedidos pela concessionária da Usina Hidroelétrica de Barra Bonita, a AES-Tietê.

\section{Identificação e contagem}

Os organismos zooplanctônicos foram identificados sob microscópios ópticos e lupa estereoscópica, em laboratório, consultando bibliografia especializada: Koste (16), Nogrady (17) e José de Paggi (18) para Rotifera, Elmour-Loureiro (19) - Cladocera and Reid (20), Silva (21) e Santos-Silva (22) - Copepoda. Para a contagem, foram feitas subamostragens das amostras: $1 \mathrm{~mL}$ em câmara de Sedgewick-Rafter para os rotíferos e náuplios, sob microscópio, e de $5 \mathrm{~mL}$ em cubetas de acrílico para os microcrustáceos, sob lupa estereoscópica.

\section{Análise dos dados}

Análises estatísticas descritivas foram aplicadas aos dados das variáveis ambientais e correlatos (físico-químicas, transparência e teor de clorofila-a) e ainda, na abundância dos grupos zooplanctônicos. 0 teste não paramétrico de Mantel foi aplicado sobre matrizes de dissimilaridade calculadas para a abundância do zooplâncton (índice de Bray Curtis) e as variáveis ambientais (distância euclidiana) com uso de 999 permutações (referências), entretanto não se verificaram correlações significativas. Assim, utilizou-se análise de correspondência canônica (ACC) para buscar correlações entre a abundância do zooplâncton e as variáveis ambientais, e a significância das variáveis canônicas $(\mathrm{p}<0,1)$ foi obtida usando os recursos computacionais que avaliaram mil permutações. Nessa última análise, em virtude da baixa abundância das espécies encontradas, optou-se em realizar uma somatória destas, representadas à mesma altura de grandes grupos (Rotifera, Cladocera e Copepoda). Ambas as análises foram realizadas no software de livre distribuição denominado "R Cran Project (23)".

\section{Resultados}

Ao analisar os dados de cota altimétrica e vazão defluente do reservatório de Barra Bonita no período de estudo, pôde-se verificar uma variação sazonal típica de reservatório de acumulação, com maiores valores de cota altimétrica entre abril e agosto (450,98 $\pm 18,82 \mathrm{~m})$, menores entre setembro e janeiro $(448,33 \pm 57,22 \mathrm{~m})$ e novamente com um aumento entre fevereiro e março $(450,36 \pm 14,41 \mathrm{~m})$, associadas ao regime pluviométrico. As vazões médias foram relativamente estáveis entre abril e janeiro $\left(305,51 \pm 48,21 \mathrm{~m}^{3} \cdot \mathrm{s}^{-1}\right)$, com picos entre fevereiro e março $\left(540,86 \pm 132,96 \mathrm{~m}^{3} . \mathrm{s}^{-1}\right)$. 0 local estudado apresentou variação de cota altimétrica de aproximadamente $1,5 \mathrm{~m}$. Ambas as variáveis hidrológicas, a cota e a vazão, estiveram relacionadas à variação sazonal da pluviosidade, a qual apresentou maiores valores acumulados mensais no verão (jan./mar.2007 = $1.078 \mathrm{~mm}$; dez. 2007/jan. $2008=600 \mathrm{~mm}$ ), contando ainda com fortes chuvas atípicas no inverno (jul./2007 = $312 \mathrm{~mm}$ ), que de modo geral, junto do outono e primavera (abril./out. $2007=336 \mathrm{~mm}$ ), apresentaram baixa frequência e intensidade pluviométrica.

Na questão da comunidade de zooplâncton, foi registrado um total de 24 táxons zooplanctônicos. Rotifera representou metade desse número (12 espécies), seguido de oito espécies de Cladocera e quatro de Copepoda. As seguintes espécies apresentaram frequência de ocorrência maior que 70\%: Conochilus coenobasis Skorikov, 1914, Conochilus unicornis Rousselet, 1892, Brachionus calicyflorus Pallas, 1766, Filinia opoliensis Zacharias, 1898, Keratella cochlearis Gosse, 1851 e Polyarthra vulgaris Carlin, 1943 entre os rotíferos, e Bosmina hagmanni Stingelin, 1904 e Ceriodaphnia cornuta Sars, 1886 entre os cladóceros. Para os copépodes, as formas larvais e jovens foram frequentes ( $>70 \%$ ), por outro lado, as formas adultas foram registradas em 
baixa frequência e abundância. Entre os Cyclopoida encontrou-se: Thermocyclops decipiens Kiefer, 1929, Metacyclops mendocinus Wierzejski, 1892 e Microcyclops anceps Richard, 1897, e somente Notodiaptomus iheringi Wright, 1935 para Calanoida.

Quanto à abundância, o maior valor médio foi observado para os náuplios (313 \pm 137 ind. $\mathrm{m}^{-3}$ ) e os copepoditos $\left(59 \pm 30\right.$ ind. $\left.\mathrm{m}^{-3}\right)$ de Cyclopoida, seguidos de Rotifera $\left(70 \pm 41\right.$ ind. $\left.\mathrm{m}^{-3}\right)$, Cladocera $\left(7 \pm 8\right.$ ind. $\left.\mathrm{m}^{-3}\right) \mathrm{e}$ copépodes adultos de Calanoida $\left(7 \pm 5\right.$ ind. $\left.\mathrm{m}^{-3}\right)$ e de Cyclopoida $\left(2 \pm 1\right.$ ind. $\left.\mathrm{m}^{-3}\right)$. Em relação à variação temporal da abundância total dos grupos zooplanctônicos (Gráfico 1A), os cladóceros e copépodes apresentaram picos de abundância para esses grupos zooplanctônicos, nos meses de setembro e outubro, e os rotíferos nos meses de dezembro-fevereiro (Gráfico 1A). Os cladóceros equivaleram a 112 ind. $\mathrm{m}^{-3}$ em setembro, seguido de fevereiro ( 55 ind. $\mathrm{m}^{-3}$ ), janeiro (48 ind. $\mathrm{m}^{-3}$ ) e outubro (42 ind. $\mathrm{m}^{-3}$ ). Os copépodes apresentaram valores máximos de 1.149 ind. $\mathrm{m}^{-3}$ em setembro e 578 ind. $\mathrm{m}^{-3}$ em outubro. Para os rotíferos, os picos observados equivaleram a 862 ind. $\mathrm{m}^{-3}$ em janeiro, 525 ind. $\mathrm{m}^{-3}$ em dezembro, 306 ind. $\mathrm{m}^{-3}$ em fevereiro, e ainda 212 ind. $\mathrm{m}^{-3}$ e 198 ind. $\mathrm{m}^{-3}$ em setembro e outubro respectivamente, estes últimos acompanhando os picos de microcrustáceos.

Em relação à abundância relativa (Gráfico 1B), Rotifera dominou na maioria dos meses, exceto em setembro e outubro, quando os microcrustáceos corresponderam à maioria. Em agosto e novembro não foram observados organismos nas amostras, ressaltando que estas foram observadas em sua totalidade. Fato peculiar nesses dois meses foram as baixas concentrações de oxigênio dissolvido $\left(>4 \mathrm{mg}^{-l^{-1}}\right)$ e a elevada transparência da água em agosto $(1,1 \mathrm{~m})$.

Em geral, os picos de abundância total do zooplâncton ocorreram em setembro e outubro. Vale destacar que esse período coincide com o início do período chuvoso em setembro $(16,60 \mathrm{~mm})$ e outubro (87,60 mm), após nenhuma precipitação no mês de agosto, o qual fora antecedido por um valor muito elevado em julho (312 mm), atípico para o período.

$\mathrm{Na}$ análise estatística, a ACC explicou $84 \%$ da variância dos dados na primeira variável canônica, e 13\% na segunda, totalizando 97\% (Figura 2), e nela foi possível distinguir associações de dados representando o período chuvoso e seco. Somente três variáveis apresentaram correlação significativa, a clorofila-a com a maior correlação $\left(r^{2}=0,71 ; p=0,02\right)$, seguida do $\mathrm{pH}\left(\mathrm{r}^{2}=0,65 ; \mathrm{p}=0,05\right)$ e da condutividade elétrica $\left(r^{2}=0,58 ; p=0,08\right)$. Por esse motivo, optouse em descrever apenas a variação sazonal das variáveis correlacionadas na ACC.

Para a clorofila, o valor médio observado $(28,51 \pm$ $22,91 \mu \mathrm{g}^{-1}{ }^{-1}$ ) foi bastante elevado, típico de reservatórios eutróficos, com picos máximos de 85,27 $\mu \mathrm{g} . \mathrm{l}^{-1} \mathrm{em}$ outubro e 57,14 $\mu \mathrm{g} . \mathrm{l}^{-1} \mathrm{em}$ novembro. Entre os meses de dezembro-fevereiro, e também em agosto, foram observados os menores valores, em média $12,63 \pm 0,63 \mu \mathrm{g} . \mathrm{l}^{-1}$. Nos demais meses, a média foi de 24,13 $\pm 5,10 \mu \mathrm{g} . \mathrm{l}^{-1}$.

0 valor médio do $\mathrm{pH}$ foi $6,16 \pm 0,93$, e sazonalmente, baixos valores $(<5,70)$ foram observados nos meses de abril-julho, novembro e dezembro, e valores mais altos, próximos de 7,09 $\pm 0,10$ nos demais meses agosto-outubro, janeiro e fevereiro. Por fim, para a

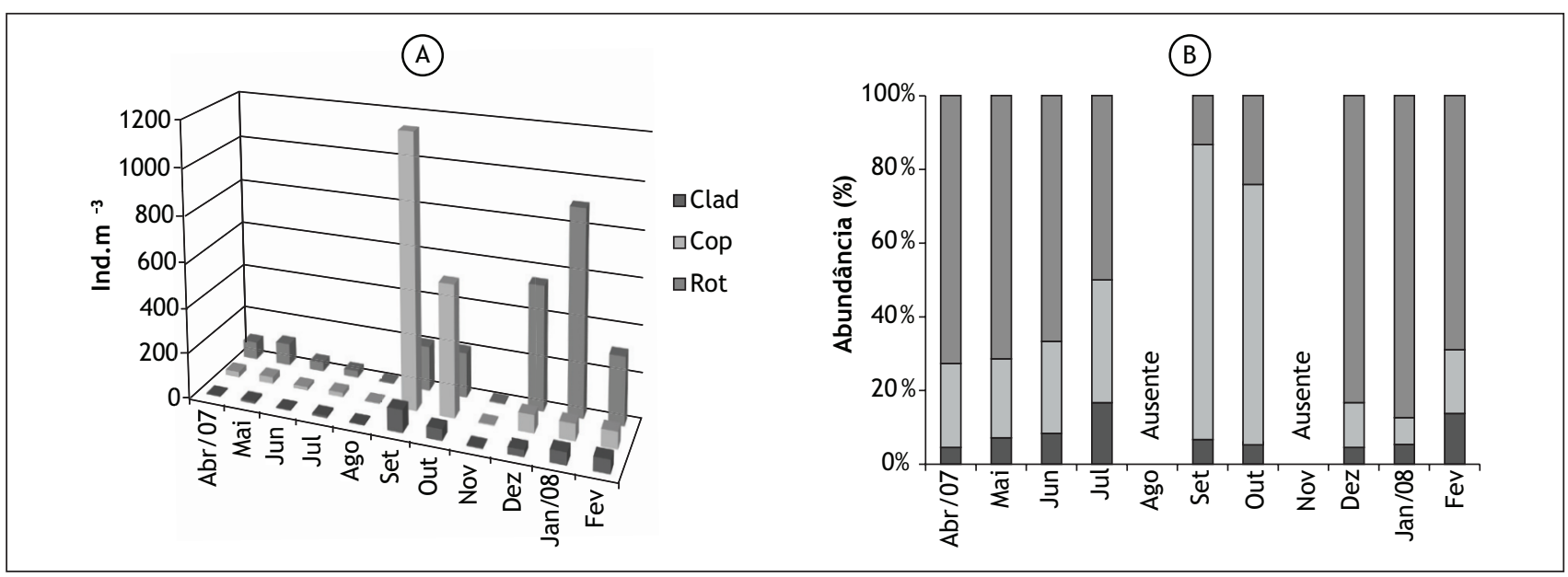

Gráfico 1 - Abundância total (A) e abundância relativa (\%) (B) de Cladocera (Clad), Copepoda (Cop) e Rotifera (Rot) entre os meses amostrados no presente estudo

Fonte: Dados da pesquisa. 
condutividade elétrica, o alto valor médio registrado $\left(549 \pm 161,00 \mu \mathrm{S} . \mathrm{cm}^{-1}\right)$ vem confirmar o grande aporte de efluentes orgânicos lançados na região metropolitana de São Paulo e outros centros urbanos. Valores acima de $700 \mu \mathrm{S} . \mathrm{cm}^{-1}$ foram observados nos meses de abril, julho e dezembro, com média geral de $740 \pm 52,91$ $\mu \mathrm{S} . \mathrm{cm}^{-1}$. Os menores valores foram observados nos meses de fevereiro $\left(230 \mu \mathrm{S} . \mathrm{cm}^{-1}\right)$ e janeiro $\left(350 \mu \mathrm{S} . \mathrm{cm}^{-1}\right)$, e nos demais meses a média foi de $540 \pm 51,76 \mu \mathrm{S}_{\mathrm{cm}} \mathrm{cm}^{-1}$.

Conforme mencionado, a ACC (Figura 1) separou as variáveis entre os períodos seco e chuvoso. Na primeira variável canônica, o pH, a clorofila e a condutividade elétrica correlacionaram-se positivamente com Copepoda e em menor valor com Cladocera, junto aos meses representantes do período seco. Inversamente, ainda na primeira variável, Rotifera esteve correlacionado com os meses representantes do período chuvoso.

Na segunda variável canônica, Cladocera associou-se positivamente com o $\mathrm{pH}$ e alguns meses de verão, e ainda julho (mês chuvoso atípico) e setembro (mesmo com baixa precipitação é normalmente o início das chuvas). Inversamente a estes, estiveram os rotíferos e copépodes, que embora tenham apresentado correlações menores, associaram-se à clorofila e à condutividade elétrica e aos meses típicos do período seco.

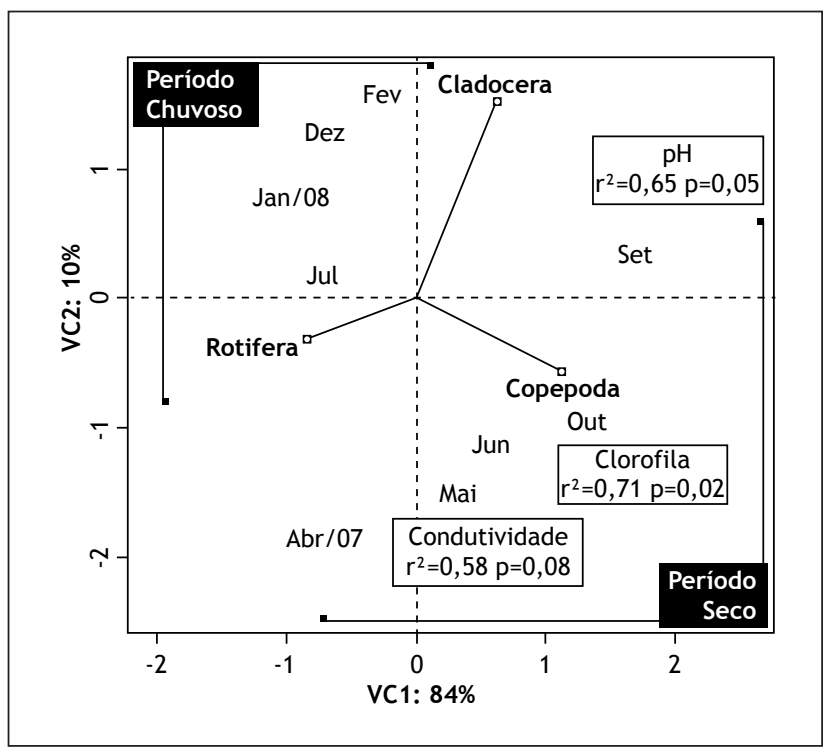

Figura 1 - Análise de correspondência canônica (ACC) para a abundância total de Cladocera, Copepoda e Rotifera e as variáveis ambientais correlacionadas significativamente entre os meses amostrados no presente estudo

Fonte: Dados da pesquisa.

\section{Discussão}

A elevada condutividade elétrica média registrada no estudo é superior ao dos outros rios tributários do Rio Paraná, sendo o reflexo da intensa poluição orgânica (8) que mostra a pouca eficiência das agências de saneamento básico em fazer boa gestão ambiental na questão dos efluentes domésticos. Os baixos valores de $\mathrm{pH}$, em alguns meses possivelmente, estiveram associados à decomposição da matéria orgânica disponível, e ainda à elevada produtividade primária refletida nos altos valores de clorofila-a. 0 fitoplâncton dispõe de nutrientes em excesso para seu desenvolvimento, e, no trecho estudado, onde se inicia a represa, ocorre a redução da velocidade da água e sedimentação de parte dos sólidos em suspensão, oferecendo condições mais propícias para seu desenvolvimento. Ao se compararem os valores obtidos com represas situadas em outros grandes rios tributários da bacia do alto Rio Paraná, porém, sem grandes centros urbanos à montante, observam-se valores bem inferiores de clorofila-a, condutividade elétrica e $\mathrm{pH}$. Exemplos seriam as represas de Furnas no Rio Grande, MG (24), São Simão no Rio Parnaíba, MG, GO (25), Corumbá no Rio Corumbá, GO (26) e na cascata de represas do Rio Paranapanema, SP, PR $(27,28)$.

Os valores de abundância registrados neste estudo foram bastante inferiores aos verificados na represa de Barra Bonita por Matsumura-Tundisi \& Tundisi (11) e Santos-Wisniewski and Rocha (13), alguns anos atrás, em estações de coleta situadas nas regiões de transição dessa represa, porém, mais a jusante do sítio amostral deste estudo. Ambos os autores encontraram diversas espécies com abundância superior a 1.000 ind. $\mathrm{m}^{-3}$, ao passo que neste estudo o valor máximo para um táxon foi 950 ind. $\mathrm{m}^{-3}$, para os náuplios de Calanoida. No trecho alto do Rio Paranapanema (SP), um rio mais preservado (não poluído) se comparado ao Rio Tietê, Casanova and Henry (5), encontraram abundâncias superiores a do presente estudo, assim como Serafim-Júnior (29) em um trecho do Rio Itajaí-Açu, SC. De maneira geral, os estudos apontam que, nos ambientes lóticos, as taxas dispersivas são maiores que as reprodutivas, e nisso torna-se comum encontrarmos baixa abundância de zooplâncton, representados, em especial, por formas imaturas.

A dominância dos rotíferos em termos de riqueza e abundância é um padrão comum nos ambientes aquáticos continentais (30). Assim, ao comparar nossos resultados com os de Matsumura-Tundisi and 
Tundisi (10), realizado mensalmente entre jul.1985/ jun.1986 em três pontos de coleta na represa de Barra Bonita, a riqueza e abundância obtidas foram bastante inferiores. Um dos pontos de coleta do estudo realizado por Matsumura-Tundisi and Tundisi, situado no braço formado pelo Rio Tietê, localizava-se cerca de $20 \mathrm{~km}$ em linha reta a jusante do local do presente estudo. Nesse local, os autores encontraram 32 espécies de rotíferos, 11 de cladóceros e seis de copépodes. Para os rotíferos, observaram elevadas abundâncias de algumas espécies com potencial de bioindicador de locais eutróficos, como Brachyonus calicyflorus, corroborando com este estudo. Outras espécies de rotíferos foram dominantes em comum, tais como Conochilus unicornis, Conochilus coenobasis e Keratella cochlearis. Comparando entre os cladóceros, a dominância dos gêneros Bosmina, Ceriodaphnia e Diaphanosoma foi similar.

Dentre os copépodes, destacou-se a única espécie de Calanoida com representantes adultos, Notodiaptomus iheringi. Segundo Matsumura-Tundisi and Tundisi (11), essa espécie pode ter substituído outras espécies de Calanoida graças ao aumento da carga de efluentes orgânicos nos corpos hídricos do Estado de São Paulo. De fato, uma das espécies que tem desaparecido nos rios e represas com esse estado de contaminação ambiental, é Notodiaptomus conifer, também não observada neste trabalho. Matsumura-Tundisi and Tundisi (11) apontam como principais causas o aumento de poluição nos corpos de água, no caso do Rio Tietê, em especial o aumento da condutividade elétrica.

Embora a condutividade tenha apresentado relação positiva com os copépodes, destaca-se que, numericamente eles foram representados por formas imaturas em grande parte, comuns no zooplâncton de quase qualquer corpo hídrico, pois as formas adultas são menos abundantes principalmente em ambientes lóticos, e sua sensibilidade às mais variadas condições são mais aguçadas. No local amostral deste estudo, o efeito da condutividade elétrica pode ser ainda mais agravante, visto que há duas razões: $1^{\underline{a}}$ ) o elevado valor médio geral observado; $2^{\underline{a}}$ ) um significativo aumento quando se compara ao diagnosticado por Matsumura-Tundisi and Tundisi (11) para o ano de 2002 nessa represa, $370 \mu \mathrm{S} . \mathrm{cm}^{-1}$. Assim, o maior valor registrado neste trabalho pode ser explicado pela predominância de condições típicas lóticas com maior concentração de poluentes do que no local estudado por Matsumura-Tundisi and Tundisi (11), em porções mais lênticas e a jusante. Não só pela condutividade elétrica, mas também visualmente, o efeito do impacto antrópico e descaso dos órgãos competentes, a poluição no local é intensa, haja vista que grandes quantidades de resíduos sólidos (lixo) foram observados a deriva. A coloração da água no local é escura e negra em alguns meses, com liberação constante de bolhas de gases na coluna de água, possivelmente de metano e outros gases oriundos do processo de decomposição. Entretanto no período chuvoso (janeiro e fevereiro), o aspecto da água é mais amarelado e os valores de condutividade elétrica são menores $\left(290 \mu{\left.\mathrm{S} . \mathrm{cm}^{-1}\right)}^{-1}\right.$ refletindo o efeito de diluição. Tundisi, Matsumura-Tundisi e Abe (8) mencionam esse efeito de diluição em 114 rios tributários que desembocam na represa de Barra Bonita, sendo responsáveis por sua heterogeneidade espacial. A presença desses gases e a baixa concentração de oxigênio dissolvido, podem ser a causa da ausência de organismos zooplanctônicos nos meses de agosto e novembro, condições pouco propícias para o desenvolvimento desses organismos.

$\mathrm{O}$ pH também foi correlacionado com a abundância do zooplâncton, e em condições de intensa poluição, como no presente trabalho, essa variável assumiu elevada importância, principalmente sobre rotíferos e copépodes, relacionado por exemplo, às trocas osmóticas. Em geral, os valores de pH tenderam à acidez $(6,15 \pm 0,93)$. Essa variável geralmente apresenta pequenas oscilações em rios com pouca interferência humana, o que não é o caso do Rio Tietê, especialmente no local estudado. Sobre a clo-

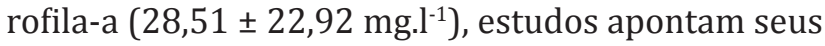
efeitos sobre o zooplâncton em geral, principalmente se ela for representada em partes por algas com baixa palatabilidade para esses organismos, como as Cyanophyceae (31). Na bacia do alto Tietê, Sant'anna (32), registraram a ocorrência de 48 espécies de cianobactérias; dentre estas, 17 consideradas potencialmente tóxicas, e assim, poderiam interferir na estrutura e composição do zooplâncton.

Em suma, os valores de riqueza e abundância de zooplâncton encontrados no presente estudo foram bem inferiores em relação a estudos similares realizados na represa de Barra Bonita e em outros ecossistemas aquáticos da bacia do alto Rio Paraná. As próprias condições lóticas do local de amostragem favorecem maior dispersão dos organismos, em relação às taxas reprodutivas. Contudo, os fortes efeitos da poluição no local representam outro agravante para a comunidade zooplanctônica, sendo também 
corroborados pelos elevados valores de condutividade elétrica, baixos valores de $\mathrm{pH}$ e oxigênio dissolvido em alguns meses, e elevado teor de clorofila-a indicando uma grande riqueza de algas. Mas, essas algas podem não ser de boa qualidade para a maioria do zooplâncton, como foi apontado em diversos trabalhos sobre o fitoplâncton em Barra Bonita.

Conforme a bibliografia disponível, a quantidade de ions disponíveis, nesse caso mensurado pela condutividade elétrica, limita algumas espécies do zooplâncton, ao mesmo tempo em que algumas, como as formas jovens, são bastante tolerantes. No período chuvoso, ocorreu uma atenuação dessas variáveis, em virtude da diluição do maior volume de água no Rio Tietê, e o inverso, no período seco, com concentração dessas espécies. Finalmente, a persistência de algumas espécies zooplanctônicas, especialmente de microcrustáceos, merecem ser mais bem investigadas, dadas as condições desfavoráveis anteriormente citadas. Elevados valores de clorofila-a corroboram a classificação eutrófica da represa (8), e de maneira geral, seu aumento favorece o desenvolvimento de organismos que se alimentam amplamente de fitoplâncton de baixa qualidade, como alguns microcrustáceos, e ainda fungos e bactérias associados aos detritos. A presença de numerosas lagoas adjacentes no local estudado certamente apresenta importante contribuição para a fauna zooplanctônica do Rio Tietê, justificando maiores investigações, dadas as adversidades e complexidade ambiental nessa importante represa do Estado de São Paulo.

\section{Agradecimentos}

Em especial, os autores agradecem à Capes (Coordenação de Aperfeiçoamento de Pessoal de Nível Superior) pela bolsa de mestrado da primeira autora, e ao técnico de laboratório Sr. Ricardo André dos Santos Teixeira, pelo seu apoio logístico nos trabalhos de campo.

\section{Referências}

1. Armengol J, Garcia JC, Comerma M, Romero M, Dolzs J, Roura M, et al. Longitudinal processes in canyon type reservoirs: the Case of Sal (N.E. Spain). In: Tundisi JG, Straskraba M. (Coord.). Theoretical reservoir ecology and its applications. Leiden. Rio de Janeiro: Brazilian Academy of Sciences, International Institute of Ecology and Backhuys Publishers; 1999. p. 313-45.
2. Marzolf RG. Reservoir as environments for zooplankton. In: Thornton KW. Perspectives on reservoir limnology. In: Thorton KW, Kimmel BL, Payne FE. (Coord.). Reservoir limnology: ecological perspectives. New York: John Wiley Sons Inc; 1990. p. 195-208.

3. Thornton WK. Perspectives on reservoir limnology. In: Thornton KW, Kimmel BL, Payne EF. (Coord.). Reservoir limnology: ecological perspectives. New York: John Wiley Sons Inc; 1990. p. 1-13.

4. Panarelli E, Casanova SMC, Nogueira MG, Mitsuka PM, Henry R. A comunidade zooplanctônica ao longo de gradientes longitudinais no Rio Paranapanema/ Represa de Jurumirim (São Paulo, Brasil). In: Henry R. (Coord.). Ecótonos nas interfaces dos ecossistemas aquáticos. Rima. São Carlos; 2003. p. 129-60.

5. Casanova SM, Henry R. Longitidunal distribution of Copepoda populations in the transition zone of Paranapanema River and Jurumirim Reservoir (São Paulo, Brazil) and interchange with two lateral lakes. Braz J Biol. 2004;64(1):11-26.

6. Martins G, Henry R. Composição e abundância do zooplâncton em três lagoas laterais ao Rio Paranapanema na zona de sua desembocadura na Represa de Jurumirim (São Paulo). In: Chellappa NT, Chellappa S, Passavante JZO (Coord.). Ecologia aquática tropical. Natal, RN: Serv. Graf.; 2004. p. 53-72.

7. De Nadai R, Henry R. Temporary fragmentation of a marginal lake and its effects on zooplankton community structure and organization. Braz J Biol. 2009;69(3): 819-35.

8. Tundisi JG, Matsumura-Tundisi T, Abe DS. The ecological dynamics of Barra Bonita (Tietê River, SP, Brazil) reservoir: implications for its biodiversity. Braz J Biol. 2008;68(4):1079-98.

9. PanhotaRS, Bianchini-JrI,VieiraAAH.Glucoseuptakeand extracellular polysaccharides (EPS) produced by bacterioplankton from an eutrophic tropical reservoir (Barra Bonita,SP-Brazil). Hydrobiologia.2007;583(1):22330. doi:10.1007/s10750-006-0532-2.

10. Matsumura-Tundisi T, Tundisi JG. Plankton richness in a eutrophic reservoir (Barra Bonita Reservoir, SP, Brazil). Hydrobiologia. 2005;542: 367-78. doi: 10.1007/1-4020-4111-X_31.

11. Barbosa FAR, Padsak J, Espindola ELG, Borics G, Rocha O. The cascading reservoir continuum concept (CRCC) and its application to the River Tiete Basin, São Paulo State, Brazil. In: Undisi JG, Straskraba M. (Ed.). Theoretical reservoir ecology and its applications. São Carlos: [s.n.]; 1999. p. 425-37. 
12. Matsumura-Tundisi T, Tundisi JG. Calanoida (Copepoda) species composition changes in the reservoirs of São Paulo State (Brazil) in the last twenty years. Hydrobiologia. 2003;504(1-3):215-22. doi: 10.1023/B:HY DR.0000008521.43711.35.

13. Tundisi JG. Gerenciamento integrado de bacias hidrográficas e reservatórios - estudos de caso e perspectivas. In: Nogueira MG, Henry R, Jorcin A. (Coord.). Ecologia de reservatórios: impactos potenciais, ações de manejo e sistemas em cascata. São Carlos: Rima; 2005. p. 1-21.

14. Santos-Wisniewski MJ, Rocha O. Spatial distribution and secondary production of Copepoda in a tropical reservoir: Barra Bonita, SP, Brazil. Braz J Biol. 2007;67(2):223-33.

15. Talling JF, Driver D. Some problems in the estimation of chlorophyll a in phytoplankton. In: Proceedings, Conference of primary productivity measurements in marine and freshwater. Hawaii: USAEE; 1961. p. 142-6.

16. Koste W. Rotatoria. Stuttgart: Gebruder Bosntraeget; 1995.

17. Nogrady T. Rotifera: biology, ecology and sistematics. The Hauge: SPB Academic Publishing; 1993.

18. Paggi JS. Rotífera. In: Lopretto EC, Tell G, editor. Ecossistemas de aguas continentales. Metodologias para su estúdio 2. La Plata: Ediciones Sur; 1995. p. 643-67.

19. Elmoor-Loureiro LMA. Manual de identificação de cladóceros límnicos do Brasil. Taguatinga: Universa; 1997.

20. Reid JW. Chave de identificação para as espécies continentais sulamericanas de vida livre da ordem Cyclopoida (Crustacea, Copepoda). Bol de Zool. 1985;9;17-143.

21. Silva WM. Diversidade dos Cyclopoida (Copepoda, Crustacea) de água doce do Estado de São Paulo: taxonomia, ecologia e genética [tese]. São Carlos: Universidade Federal de São Carlos; 2003.

22. Santos-Silva EN. Revisão das espécies do "complexo nordestinus" (Wright, 1935) de Notodiaptomus Kiefer, 1936 (Copepoda: Calanoida: Diaptomidae) [tese]. São Paulo: Universidade de São Paulo; 2000.

23. R Development Core Team. A language and environment for statistical computing. Vienna, Austria, R Foundation for Statistical Computing ISBN 3-90005107-0 [online] 2006 [recuperado em 06 mar. 2010]. Disponível em: http://www.R-project.org.
24. Santos RM, Rocha GS, Rocha O, Santos-Wisniewski MJ. The influence of net cage fish cultures on the diversity of the zooplankton community in the furnas hydroelectric reservoir. Aquac Res. 2009;40:753-61. doi: 10.1111/j.1365-2109.2008.02148.x.

25. Pinto-Coelho RMP. Origens e efeitos do aporte externo de nutrientes em um reservatório tropical de grande porte: reservatório de São Simão (MG/GO). In: Nogueira MA, Henry R, Jorcin A. (Coord.). Ecologia de reservatórios: impactos potenciais, ações de manejo e sistemas em cascata. São Carlos: Rima; 2005. p. 127-64.

26. Bonecker CC, Lansac-Tôha FA, Velho LFM, Rossa DC. The temporal distribution pattern of copepods in Corumbá reservoir, State of Goias, Brazil. Hydrobiologia. 2002;156(5):375-84. doi: 10.1007/0-306-47537-5_31.

27. Sampaio EV, Rocha O, Matsumura-Tundisi T, Tundisi JG. Composition and abundance of zooplankton in the limnetic of seven reservoir of the Paranapanema River. Braz J Biol. 2002;62(3):525-45.

28. Nogueira MG, Oliveira PCR, Britto YCT. Zooplankton assemblages (Copepoda and Cladocera) in a cascade of reservoirs of a large tropical river (SE Brazil). Limnética. 2008;27:151-70.

29. Serafim-Júnior M, Perbiche-Neves G, Brito L, Ghidini AR. Zooplâncton do Rio Itajaí-Açú a jusante da cidade de Blumenau, Santa Catarina, Brasil. Estud Biol. 2006;28(65):47-56.

30. Rocha O, Sendacz S, Matsumura-Tundisi T. Composition, biomass and productivity of zooplankton in natural lakes and reservoirs of Brazil. In: Tundisi JG, Bicudo CEM, Matsumura-Tundisi T. Limnology in Brazil. São Paulo: ABC/SBL; 1995. p. 151-65.

31. Perbiche-Neves G, Serafim-Júnior M, Ghidini AR, Brito L. Spatial and temporal distribution of Copepoda (Cyclopoida and Calanoida) of an eutrophic reservoir in the basin of upper Iguaçu River, Paraná, Brazil. Acta Limnol Bras. 2007;19(4):393-406.

32. Sant'anna CL, Melcher SS, Carvalho MC, Gemelgo MP, Azevedo MTP. Planktic Cyanobacteria from upper Tietê basin reservoirs, SP, Brazil. Rev Bras Bot. 2007;30:1-17. 